\title{
Statistical models relating peak expiratory flow rates to age, height, and weight in men and women
}

\author{
C. K. GUPTA AND NEERAJ MATHUR \\ From the V.P. Chest Institute, University of Delhi, India
}

SUMMARY An epidemiological survey of 1239 normal subjects without respiratory symptoms was undertaken in an urban locality of New Delhi in 1974. The subjects were divided into males aged under or over 22 and females under or over 17. Various statistical models were calculated to relate peak expiratory flow rate to the age, height, and weight of the subjects in each group. The linear model was simple, convenient, and adequately explained the variation in peak expiratory flow rate.

A linear additive model is usually preferred to other models to relate measures of ventilatory function to physical characteristics because it is simple and convenient. Normal standards have so far been established on the basis of a linear model $.^{1-7} \mathrm{Khosla},{ }^{8}$ however, used a multiplicative model to form indices of ventilatory functions $\mathrm{FEV}_{\mathbf{1}}, \mathrm{FVC}^{*}$ and $\mathrm{FEV}_{\mathbf{1}} / \mathrm{FVC}$ in a study of men in the steel industry. Cole ${ }^{2}$ added the interaction term of age/height to his regression models relating $F E V_{1}$ and FVC to physical characteristics, and in a subsequent study ${ }^{10}$ he preferred a proportional model. Malik et al, ${ }^{11}$ when relating peak expiratory flow rate (PEFR) to physical characteristics in normal adults, used a polynomial of third degree in age with height. These studies suggest that the models relating ventilatory function to age, height, and weight should be explored further.

In this paper we study various models relating PEFR to age, height, and weight and compare them with each other.

\section{Material and methods}

This study consisted of 1427 normal individuals derived from an epidemiological survey conducted in a compact urban locality of New Delhi in 1974. The results of this survey have been reported by us earlier. ${ }^{12}$ The sampling frame was an updated list of households obtained by the Malaria Eradication Programme; the sampling method was to select a household at random and then to sample systematically using a sampling fraction of 1 in 120 . All individuals aged over 3 in the selected households were included in the study population.

" $F E V_{1}=$ forced expiratory volume in one second.

FVC $=$ forced vital capacity.
Two schedules were completed, one for the household and one for the individual; the questionnaire for the individuals was based upon the British Medical Research Council's bronchitis questionnaire. ${ }^{13}$

A normal subject was defined as one who did not have persistent cough or phlegm first thing in the morning and who did not report haemoptysis, breathlessness, wheezing, or nasal catarrh at the time of the interview and did not report a history of heart disease or any respiratory disorder such as bronchitis, pneumonia, pleurisy, tuberculosis, asthma, or bronchiectasis during the previous three years. The normal subjects were divided into four sex and age groups: men aged 22 and over; youths and boys aged 21 and under; women aged 17 and over; and girls aged 16 and under.

Height (standing without shoes) and weight were measured in inches and kilograms respectively. The height was converted to centimetres at the time of analysis. The PEFR was measured by the Wright peak flow meter recording the maximum of five readings. All readings were taken and recorded by one investigator to minimise interobserver variation as shown by Fairbairn et al. ${ }^{14}$

The statistical models calculated are given in Table 1 where the dependent variable is PEFR measured in litres per minute and the regressor variables are age in years, height in $\mathrm{cm}$, weight in $\mathrm{kg}$, or functions of these such as exponents, products, or logarithms. The models were fitted by the method of least squares and the sum of squares of PEFR after fitting the model (PEFR SS) and the residual standard deviations were calculated.

A number of subjects in the selected household did not provide a complete record because they were 
Table 1 Models relating peak expiratory flow rate to physical characteristics

\begin{tabular}{|c|c|}
\hline Models & Description \\
\hline $\begin{array}{l}\text { (1) Linear in age } \\
\text { (2) Linear in age, height } \\
\text { (3) Linear in age, height and weight } \\
\text { (4) Interaction (1) } \\
\text { (5) Interaction (2) } \\
\text { (6) Interaction (3) } \\
\text { (7) Proportional } \\
\text { (8) General } \\
\text { (9) Multiplicative } \\
\text { (10) Polynomial of degree } 2 \text { in age } \\
\text { (11) Polynomial of degree } 3 \text { in age with height }\end{array}$ & 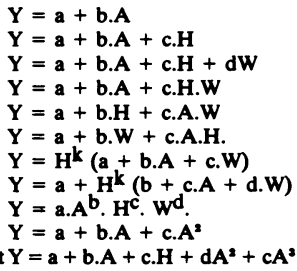 \\
\hline $\begin{array}{l}Y=\text { PEFR } \\
A=\text { age } \\
H=\text { height } \\
W=\text { weight } \\
\text { a,b,c, = regression coefficients } \\
\mathbf{K}=\text { power function }=0.5,1.0\end{array}$ & \\
\hline
\end{tabular}

either absent or unwilling to do so. In each group those normal subjects who provide a PEFR record were compared with those who did not, with respect to age, height, and weight, to ascertain whether there had been a bias in the selection of responders. The means when variances were not homogeneous.

\section{Results}

The survey selected 505 households containing 2098 individuals over 3 of whom $1427(68 \%)$ were defined as normal; of these normal subjects 188 did not provide a complete record, leaving 1239 (87\%) normal subjects in the study: 322 men, 382 women, 316 boys, and 219 girls. The means and the standard deviations for each group for age, height, weight, and PEFR are given in Table 2.

The mean values of all measures were higher for males than females and for adults than for children and youths.

The zero order correlations between these variables within each group are given in Table 3. In all groups the correlations between PEFR and physical characteristics were statistically significant, Fisher-Behrens ' $d$ ' test ${ }^{15}$ was used to compare the

Table 2 Peak expiratory flow rates (PEFR) in 1239 normal subjects by age and sex groups with physical characteristics (means and standard deviations)

\begin{tabular}{llllrc}
\hline Sex and & $\begin{array}{l}\text { No. of } \\
\text { age groups }\end{array}$ & $\begin{array}{l}\text { persons } \\
(l / \text { min) }\end{array}$ & $\begin{array}{l}\text { Mean } \pm S D \\
\text { (years) } \\
\text { Mean } \pm S D\end{array}$ & $\begin{array}{l}\text { HEIGHT } \\
(\mathrm{cm}) \\
\text { Mean } \pm S D\end{array}$ & $\begin{array}{l}\text { WEIGHT } \\
(\mathrm{kg}) \\
\text { Mean } \pm S D\end{array}$ \\
\hline Boys (3-21) & 316 & 315.6 & 12.7 & 143.4 & 34.1 \\
& & \pm 134.5 & \pm 4.3 & \pm 21.3 & \pm 14.6 \\
Girls (3-16) & 219 & 246.6 & 11.1 & 134.1 & 28.4 \\
& & \pm 99.1 & \pm 3.3 & \pm 17.9 & \pm 12.0 \\
Men (22+) & 322 & 453.3 & 39.4 & 166.3 & 60.1 \\
& & \pm 104.4 & \pm 14.4 & \pm 7.1 & \pm 12.6 \\
Women (17+) & 382 & 320.0 & 34.8 & 152.5 & 50.7 \\
& & \pm 76.4 & \pm 13.8 & \pm 6.4 & \pm 10.9 \\
\hline
\end{tabular}

with the single exception of PEFR and weight in women. None of the correlations in the younger groups was less than $0 \cdot 8$, but in adults all correlations were below 0.5. Age, height, and weight were all significantly correlated with each other except that height and weight were not correlated with age in men.

Table 4 shows the proportion of the PEFR sums of squares that are explained by each model within each group. For men the linear model 3 explains $28.9 \%$; only one other model, 11 , the polynomial of third

Table 4 Per cent of sums of squares of PEFR explained by models

\begin{tabular}{|c|c|c|c|c|}
\hline Model & Men & Women & Boys & Girls \\
\hline $\begin{array}{l}\text { (1) } \\
(2) \\
(3) \\
(4) \\
(5) \\
(6) \\
(7 i) \\
(7 i i) \\
(7 i i i) \\
(7 i v) \\
(8 i) \\
(8 i i) \\
(8 i i) \\
(8 i v) \\
(9) \\
(10) \\
(11)\end{array}$ & $\begin{array}{l}20 \cdot 8 \\
26 \cdot 3 \\
28 \cdot 9 \\
27 \cdot 8 \\
17 \cdot 7 \\
25 \cdot 0 \\
28 \cdot 3 \\
28 \cdot 7 \\
27 \cdot 7 \\
25 \cdot 2 \\
28 \cdot 9 \\
28 \cdot 9 \\
28 \cdot 8 \\
28 \cdot 7 \\
25 \cdot 2 \\
22 \cdot 0 \\
29 \cdot 8\end{array}$ & $\begin{array}{l}20 \cdot 6 \\
23.6 \\
24 \cdot 8 \\
23 \cdot 9 \\
17 \cdot 2 \\
21 \cdot 5 \\
24 \cdot 3 \\
24 \cdot 5 \\
23 \cdot 5 \\
21 \cdot 1 \\
24 \cdot 7 \\
24 \cdot 7 \\
24 \cdot 6 \\
24 \cdot 6 \\
23 \cdot 8 \\
21 \cdot 8 \\
24 \cdot 4\end{array}$ & $\begin{array}{l}\mathbf{7 4 \cdot 3} \\
83 \cdot 0 \\
83 \cdot 8 \\
82 \cdot 5 \\
84 \cdot 0 \\
82 \cdot 8 \\
82 \cdot 8 \\
83 \cdot 9 \\
84 \cdot 5 \\
84 \cdot 7 \\
84 \cdot 0 \\
84 \cdot 4 \\
84 \cdot 6 \\
84 \cdot 7 \\
84 \cdot 1 \\
74 \cdot 3 \\
84.0\end{array}$ & $\begin{array}{l}63.4 \\
70 \cdot 7 \\
73 \cdot 1 \\
71 \cdot 9 \\
72.9 \\
72.2 \\
72.2 \\
72.9 \\
73.0 \\
72.3 \\
73.2 \\
73.2 \\
73.0 \\
72.6 \\
75.4 \\
63.4 \\
71.1\end{array}$ \\
\hline
\end{tabular}

Table 3 Zero order correlation coefficients between physical characteristics and PEFR for normal subjects in age and sex groups

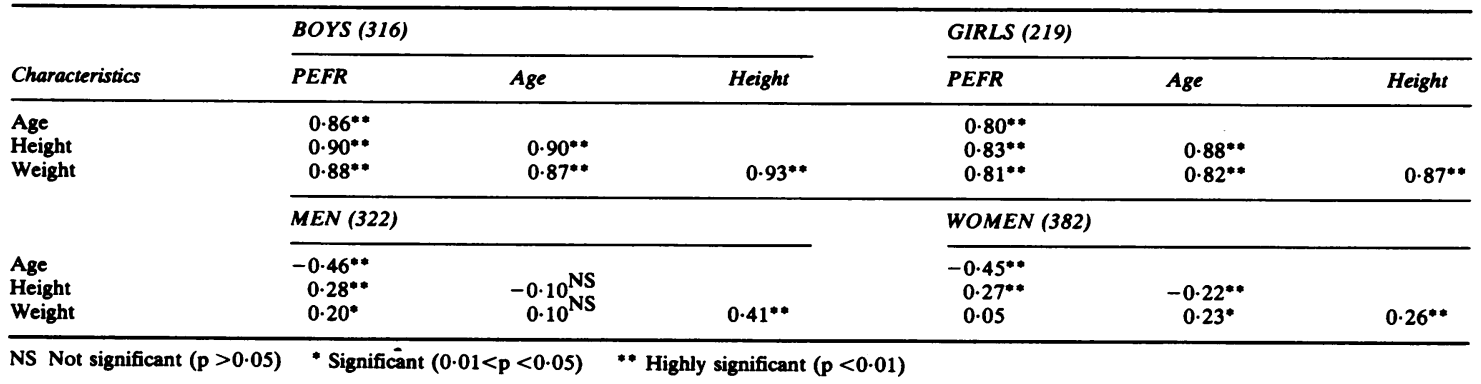


degree, accounts for a larger proportion of the variance and the difference is not significant. For women the linear model 3 is the best fit with $24.8 \%$ of the sums of squares explained. Among the younger group the linear model 3 explains $83 \cdot 8 \%$ for boys and $73.1 \%$ for girls and no other model produces a significant improvement in these results.

The expected PEFR for specified ages was determined from the linear models in the present study for men and women for fixed height (men-160 cm; women-150 cm) and weight (men-60 kg; women-50 kg). These are compared (Figs. 1 and 2) with those based on the models proposed by other Indian and Western workers.

The physical characteristics of those normal subjects who had a PEFR recorded are compared with those who did not have this done. For boys and girls the responders were older, taller, and heavier than the non-responders. The men were not different in age and height, but the responders were lighter in weight. The women were not different in height and weight, but the responders were younger.

\section{Discussion}

All the models explained about $70-80 \%$ of PEFR SS in children. In adults, however, these models accounted for about $20-30 \%$ of PEFR SS, leaving a substantial amount to be accounted for either by factors not included in the model or by random variation. In women this was not due to smoking since there was only one woman who smoked.12 There was no other independent variable evidently responsible for this unaccounted PEFR SS in adults, which was therefore likely to be due to random variation. Height and weight are stabilised in adults and do not account for as large a proportion of PEFR SS as they do in childhood. This was also reflected in the poor correlations between PEFR and height and weight in adults.

On the whole, all the models were found to have similar predictive capacity to determine PEFR in the normal population since there were not wide variations in the residual sums of squares within the age and sex groups.

All these models have done fairly well in our study, but none of them was consistently superior to the other models in all the sex and age groups. The linear model 3 , in age, height, and weight, was best in women, second-best in men, and close to second-best in boys and girls. The gain of the best models over the linear model was slight and differed between the groups and is not important enough to recommend their use as they are certainly more complicated.

The linear model involving age, height, and weight is, therefore, the recommended method by which

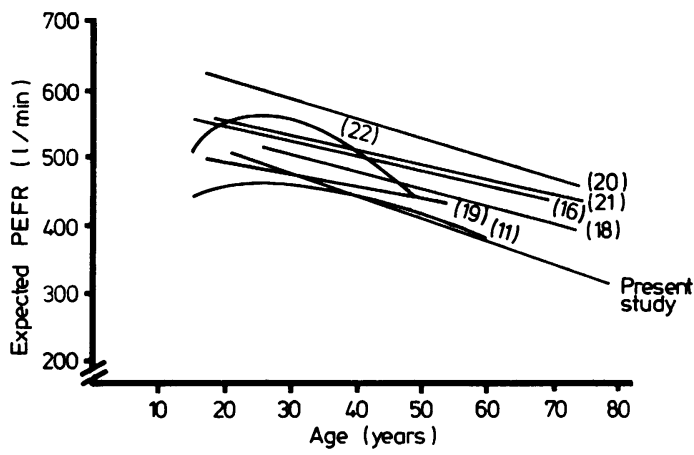

Fig. 1 Expected PEFR in men with height $(165 \mathrm{~cm})$ and weight $(60 \mathrm{~kg})$ based on the models by different workers.

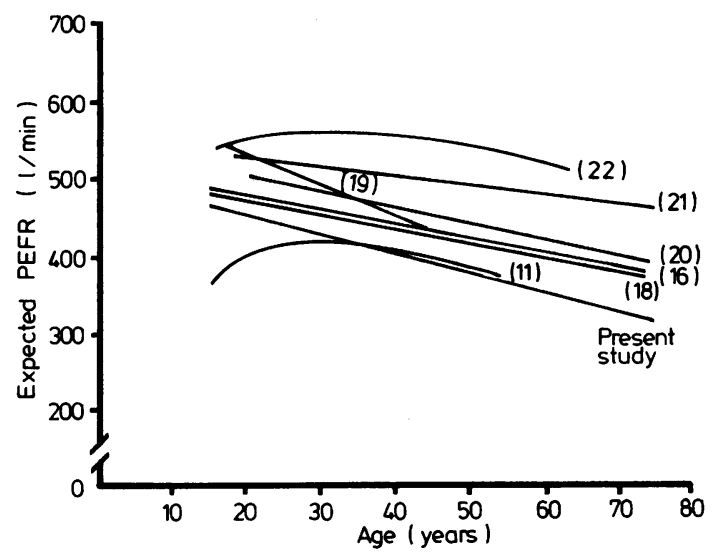

Fig. 2 Expected PEFR in women with height $(150 \mathrm{~cm})$ and weight $(50 \mathrm{~kg})$ based on the models by different workers.

PEFR should be estimated in normal individuals and it should be the best method of standardisation. Such a model, with or without weight, has been frequently used to determine PEFR in normal subjects and to standardise differences in groups with respect to physical characteristics. ${ }^{71617}$

The formulae recommended for use in India are:

Residual SD of $\hat{Y}$

For men: $\quad \hat{\mathrm{Y}}=106-3.31 \mathrm{~A}+2.34 \mathrm{H}+1.47 \mathrm{~W}(89)$

For women: $\hat{Y}=111-2.50 \mathrm{~A}+1.65 \mathrm{H}+0.85 \mathrm{~W}$ (67)

For boys: $\hat{\mathbf{Y}}=-287+6.76 \mathrm{~A}+3.07 \mathrm{H}+2.21 \mathrm{~W}$

For girls: $\quad \hat{\mathbf{Y}}=-170+6.27 \mathrm{~A}+2.03 \mathrm{H}+2.65 \mathrm{~W}$

$\hat{\mathbf{Y}}=$ expected PEFR $(\mathrm{l} / \mathrm{min}) ; \mathrm{A}=$ age (years); $\mathrm{H}=$ height $(\mathrm{cm})$; and $\mathrm{W}=$ weight $(\mathrm{kg})$. 
Our expected PEFR values were comparable with those based on a polynomial of third degree in age with height. ${ }^{11}$ These were lower compared with those of Kamat et al. ${ }^{10}$ The differences may be explained by the fact that their subjects were picked up by judgment-sampling to conform to the age structure of the Government of India Census, 1961, and later they noticed that they had excluded nutritionally unbalanced subjects. Our values were also lower than those of Western workers ${ }^{18-22}$ (see Figs. 1 and 2). This

\section{References}

${ }^{1}$ Committee on Rating of Mental and Physical Impairment. The respiratory system. JAMA 1965; 194: 919-32.

${ }^{2}$ Cotes JE, Rossiter CE, Higgins ITT, Gilson JC. Average, normal values for the forced expiratory volume in white Cancasian males. Br Med J 1966; i: 1016-9.

${ }^{3}$ Jain SK, Gupta CK. Age, height and body weight as determinants of ventilatory norms in healthy men above 40 years of age. Indian J Med Res 1967; 55: 599-611.

4 Jain SK, Ramiah TJ. Prediction of ventilatory norms in healthy boys 7-14 years age. Indian J Chest Dis 1968; X2: 69-79.

5 Jain SK, Ramiah TJ. Normal standards of pulmonary function tests for healthy Indian men 15-40 years old: comparison of different regression equations (prediction formulae). Indian J Med Res 1969; 57: 1453-66.

${ }^{6}$ Lowe CR, Pelmear PL, Campbell H, Hitchens RAN, Khosla T, King TC. Bronchitis in two integrated steel works I. Ventilatory capacity, age, and physique of non-bronchitis men. Br J Prev Soc Med 1968; 22: 1-11.

${ }^{7}$ Amin SK, Pande RS. Peak expiratory flow rate in normal subjects. Indian J Chest Dis 1978; XX2: 80-3.

${ }^{8}$ Khosla T. Indices of ventilatory measurements. Br J Prev Soc Med 1971; 25: 203-9.

${ }^{\circ}$ Cole TJ. The influence of height on the decline in ventilatory function. Int $J$ Epidemiol 1974; 3: 145-52.

${ }^{10}$ Cole TJ. Linear and proportional regression models in the prediction of ventilatory function. $J$ R Stat Soc $A$ 1975; 138: 297-338.

${ }^{11}$ Malik SK, Jindal SK, Jindal V, Bansal S. Peak expiratory flow rates in healthy adults. Indian J Chest Dis 1975; XVII4: $166-71$. was possibly due to genetic and environmental factors, as shown by Cotes et $a^{23}$ in the case of other ventilatory functions.

We thank Dr. T. G. Radha, chief investigator of the survey, Dr. Gita Bhowmick, Consultant, Delhi University Computer Centre, and the referees of the journal for advice.

Reprints from Mr. C. K. Gupta, V. P. Chest Institute, University of Delhi, Delhi 110007, India.

${ }^{12}$ Radha TG, Gupta CK, Singh Ajit, Mathur N. Chronic bronchitis in an urban locality of New Delhi-an epidemiological survey. Indian J Med Res 1977; 66: 273-85.

${ }^{13}$ Medical Research Council Committee on the Aetiology of Chronic Bronchitis. Standard questionnaires on respiratory symptoms. $\mathrm{Br} \mathrm{Med} J$ 1960; ii: 1665.

${ }^{14}$ Fairbairn AS, Wood CM, Fletcher CM. Variability in answers to a questionnaire on respiratory symptoms. $\mathrm{Br}$ J Prev Soc Med 1959; 13: 175-93.

${ }^{15}$ Fisher RA, Yates F. Statistical tables for biological, agricultural and medical research, 6th edn. Edinburgh: Oliver and Boyd, 1970: 3-4.

${ }^{16}$ Kamat SR, Sarma BS, Raju VRK et al. Indian norms for pulmonary function. J Assoc Physicians India 1977; 25: $531-40$.

${ }^{17}$ Holland WW, Malie T, Bennet AE, Elliott A. Factors influencing the onset of chronic respiratory diseases. $\mathrm{Br}$ Med J 1969; ii: 205-8.

${ }^{18}$ Ferris BG jr, Anderson DO. Prediction values for screening tests of pulmonary function. Am Rev Respir Dis 1965; 91: 252-61.

${ }^{19}$ Elebute EA, Pearse F. Peak flow rate in Nigeria. Anthropometric determinants and usefulness in assessment of ventilatory function. Thorax 1971; 26: 597-601.

${ }^{20}$ Pelzer AM, Thomson ML. Expiratory peak flow. $\mathrm{Br} \mathrm{Med}$ $J$ 1964; ii: 123.

${ }^{21}$ Read J, Selby T. Tobacco smoking and ventilatory function of the lungs. $\mathrm{Br}$ Med J 1961; ii: 1104-8.

${ }^{22}$ Gregg I and Nunn AJ. Peak expiratory flow in normal subjects. $\mathrm{Br}$ Med J 1973; iii: 282-4.

${ }^{23}$ Cotes JE, Dabbs JM, Hall AM, Lakhera SC, Saunders MJ, Malhotra MS. Lung function of healthy young men in India. Proc $R$ Soc Lond 1975; 191 (B): 413-25. 